\title{
Simultaneous Detection of 10 Foodborne Pathogens using Capillary Electrophoresis-Based Single Strand Conformation Polymorphism
}

\author{
Mi-Hwa Oh, Hee Sung Hwang ${ }^{1}$, Boram Chung ${ }^{1}$, Hyun-Dong Paik², Sangha Han, Sun Moon Kang, \\ Jun-Sang Ham, Hyoun Wook Kim, Kuk-Hwan Seol, Aera Jang ${ }^{3}$, and Gyoo Yeol Jung ${ }^{1,4 *}$ \\ National Institute of Animal Science, Rural Development Administration, Suwon 441-706, Korea \\ ${ }^{1}$ Department of Chemical Engineering, Pohang University of Science and Technology, Pohang 790-784, Korea \\ ${ }^{2}$ Department of Food Science and Biotechnology of Animal Resource, Konkuk University, Seoul 143-701, Korea \\ ${ }^{3}$ Department of Animal Products and Food Science, Kangwon National University, Chuncheon 200-701, Korea \\ ${ }^{4}$ School of Interdisciplinary Bioscience and Bioengineering, Pohang University of Science and Technology, \\ Pohang 790-784, Korea
}

\begin{abstract}
This report outlines the development of a rapid, simple, and sensitive detection system for pathogenic bacteria using a capillary electrophoresis-based, single strand conformation polymorphism (CE-SSCP) combined with PCR. We demonstrate that this method, used with primers targeting the V4 region of the16S rRNA gene, is capable of the simultaneous detection of 10 microbes that could be associated with foodborne illness, caused by animal-derived foods: Salmonella enterica, Listeria monocytogenes, Escherichia coli O157:H7, Campylobacter jejuni, Staphylococcus aureus, Bacillus cereus, Clostridium perfringens, Yersinia enterocolitica, Vibrio parahaemolyticus, and Enterobacter sakazakii. The traditional detection techniques are time-consuming and labor-intensive, due to the necessary task of separate cultivation of each target species. As such, the CE-SSCP-PCR method, that we have developed, has the potential to diagnose pathogens rapidly, unlike the traditional technique, in order to prevent foodborne illness in a much more efficient manner.
\end{abstract}

Key words: CE, SSCP, PCR, simultaneous detection, foodborne pathogens

\section{Introduction}

The rapid and sensitive diagnosis of foodborne pathogens is important for the prevention of foodborne illnesses (Sakamoto et al., 2001), particularly as the outbreaks resulting from increased institutional food services and westernized food practices have significant economic and social impact, and there is now increased public awareness of food safety. However, conventional methods for the detection of pathogens, such as plating and biochemical tests, are labor intensive and take several days to perform (Gracias and Mackillip, 2004). Immunoassays and molecular methods have therefore been developed to allow the rapid analysis of pathogens, and intensive study into the use of PCR-based methods has recently been carried out as it is both rapid and sensitive.

*Corresponding author: Gyoo Yeol Jung, Department of Chemical Engineering, Pohang University of Science and Technology, Pohang 790-784, Korea. Tel: 82-54-279-2391, Fax: 82-54-2795528, E-mail: gyjung@postech.ac.kr
Capillary electrophoresis-based single strand conformation polymorphism (CE-SSCP) may also be used to identify pathogens; it is a powerful system for the simultaneous detection of multiple microorganisms (Larsen et al., 2007; Oh et al., 2009; Shin et al., 2008, 2010; Zinger et al., 2007).

The "Standards for Processing and Ingredients of Specifications Livestock Product" (Animal Plant and Fisheries Quarantine and Inspection Agency, 2011) stipulate that the six foodborne pathogens, including Salmonella spp., Staphylococcus aureus, Vibrio parahaemolyticus, Clostridium perfringens, Listeria monocytogenes, and Escherichia coli $\mathrm{O} 157: \mathrm{H} 7$, should not be detected in edible meat or heat-treated and ready-to-eat food products. Other pathogens such as Bacillus cereus (particularly the diarrheal toxin-producing strains), Campylobacter jejuni, and Yersinia enterocolitica, which are well known to contaminate raw and processed meat (Altekruse et al., 1999; McNallay et al., 2004; Oh and Cox, 2009) and Enterobacter sakazakii, which is frequently found in infant food such as powder milk (Iversen and Forsythe, 2003; Jos 
Van et al., 2001), should also be controlled. We therefore developed a CE-SSCP protocol capable of parallel detection of the foodborne pathogens including Salmonella enterica, L. monocytogenes, E. coli O157:H7, C. jejuni, $S$. aureus, B. cereus, $C$. perfringens, $Y$. enterocolitica, $V$. parahaemolyticus, and E.sakazakii. This method may have potential as a suitable early warning system for foodborne outbreaks.

\section{Materials and Methods}

\section{Bacterial strain culture and genomic DNA isolation}

Ten foodborne pathogenic bacteria were selected for this study as reference strains (Table 1). Aerobic or facultative anaerobic bacteria, including Salmonella enterica, L. monocytogenes, E. sakazakii, E. coli $\mathrm{O} 157: \mathrm{H} 7$, V. parahaemolyticus, Y. enterocolitica, B. cereus, and $S$.

Table 1. Bacterial strains used in this study

\begin{tabular}{|c|c|c|}
\hline Bacteria & Serovar/strain & Source $^{1)}$ \\
\hline \multirow[t]{3}{*}{ Bacillus cereus } & & ATCC 14579 \\
\hline & & ATCC 10876 \\
\hline & & ATCC 11778 \\
\hline Campylobacter jejuni & & КССM 41773 \\
\hline \multirow[t]{2}{*}{ Clostridium perfringens } & & ATCC 3624 \\
\hline & & ATCC 13124 \\
\hline Enterobacter sakazakii & & ATCC 12868 \\
\hline \multirow[t]{2}{*}{ Escherichia coli } & $\mathrm{O} 157: \mathrm{H} 7$ & ATCC 43894 \\
\hline & & ATCC 27325 \\
\hline \multirow[t]{2}{*}{ Listeria monocytogenes } & serotype 1 & ATCC 19111 \\
\hline & & ATCC 15313 \\
\hline \multirow[t]{6}{*}{ Salmonella enterica } & Typhimurium & ATCC 19585 \\
\hline & Typhimurium & ATCC 13311 \\
\hline & Typhi & ATCC 6539 \\
\hline & Typhi & ATCC 33459 \\
\hline & Paratyphi C & ATCC 13428 \\
\hline & Paratyphi B & ATCC 10719 \\
\hline \multirow[t]{2}{*}{ Staphylococcus aureus } & & ATCC 25923 \\
\hline & & КССM 12214 \\
\hline \multirow{3}{*}{ Vibrio parahaemolyticus } & & ATCC 17802 \\
\hline & & ATCC 27969 \\
\hline & & ATCC 33844 \\
\hline \multirow[t]{2}{*}{ Yersinia enterocolitica } & & ATCC 23715 \\
\hline & & ATCC 27739 \\
\hline
\end{tabular}

aureus, were grown in tryptone soya broth (TSB, Difco Laboratories, USA) for $24 \mathrm{~h}$ at $37^{\circ} \mathrm{C}$. The pathogen $C$. perfringens was grown under anaerobic conditions in TSB for $24 \mathrm{~h}$ at $37^{\circ} \mathrm{C}$, while $C$. jejuni was grown microaerobically in Hunt broth (MBcell, Korea) containing 5\% horse blood (MBcell, Korea) for $48 \mathrm{~h}$ at $42^{\circ} \mathrm{C}$. The pathogen cultures were grown to concentrations of approximately $10^{8}-10^{9} \mathrm{CFU} / \mathrm{mL}$, and mixed inoculum was prepared by combining equal amounts of all 10 pathogens. DNA was extracted from $1 \mathrm{~mL}$ of the pathogen mixture using the DNeasy kit (Qiagen, Inc., USA) according to the manufacturer's instructions.

\section{PCR amplification}

The primer sets used to amplify DNA for separation analysis targeted the three different variable regions of the 16S rRNA gene (Table 2; Gillman et al., 2001). Sets of forward and reverse primers for each variable region were prepared, whereby 1 of each primer was fluorescently labeled at the 5 end with 6-carboxyfluorescein (6FAM). $P f u$ polymerase PCR premix and primers were obtained from Bioneer, Inc. (Daejeon, Korea), and PCR was performed in a $20-\mu \mathrm{L}$ reaction volume containing genomic DNA, 10 pmol of each primer (forward and reverse), $0.25 \mathrm{mM}$ of each dNTP, and $1 \mathrm{U}$ of Pfu DNA polymerase in reaction buffer. The PCR cycle was as follows: initial denaturation for $4 \mathrm{~min}$ at $95^{\circ} \mathrm{C} ; 25$ cycles of denaturation for $30 \mathrm{~s}$ at $95^{\circ} \mathrm{C}$, annealing for $30 \mathrm{~s}$ at $55^{\circ} \mathrm{C}$, and extension for $30 \mathrm{~s}$ at $72^{\circ} \mathrm{C}$; followed by a final extension for $7 \mathrm{~min}$ at $72^{\circ} \mathrm{C}$. PCR products were diluted as appropriate in nuclease-free water and used for CE-SSCP analysis.

\section{Polymer matrix preparation and CE-SSCP analysis}

Polymer matrix was prepared before $\mathrm{CE}$ analysis by dissolving various concentrations of Pluronic F108 PEOPPO-PEO triblock copolymers purchased from SigmaAldrich Inc. (USA) in $0.7 \times$ EDTA buffer (Applied Biosystems, USA). CE-SSCP analysis was performed as previously described (Oh et al., 2009). Briefly, a 1- $\mu \mathrm{L}$ sample of the amplified 16S rRNA gene from each species was mixed with $13.5 \mu \mathrm{L}$ deionized formamide (Applied Biosystems, USA) and $0.5 \mu \mathrm{L}$ ROX 500 size

Table 2. Primers used in this study

\begin{tabular}{cllc}
\hline \hline Target region & \multicolumn{1}{c}{ Forward seq. } & \multicolumn{1}{c}{ Reverse seq. } & Product Size (bp) \\
\hline V2 & 5'-GGC GGA CGG GTG AGT AA-3' & 5'-GGA CTG CTG CCT CCC GTA G-3' & 255 bp \\
V4 & 5'-TGC CAG CAG CCG CGG TAA-3' & 5'-GGA CTA CCA GGG TAT CTA AT-3' & 290 bp \\
V8 & 5'-AAC TGG AGG AAG GTG GGG AT-3' & 5'-AGG CCC GGG AAC GTA TTC AC-3' & 220 bp \\
\hline
\end{tabular}


standards (Applied Biosystems, USA); the sample mixtures were denatured at $94^{\circ} \mathrm{C}$ for 4 min followed by immediate cooling on ice for $3 \mathrm{~min}$. CE-SSCP analyses were performed using an ABI Prism 310 Genetic Analyzer using non-coated capillaries $(47 \mathrm{~cm} \times 50 \mu \mathrm{m}$; Applied Biosystems, USA), configured in accordance with the manufacturer's instructions. Samples were electrophoresed using an injection voltage of $15.0 \mathrm{kV}$, an electrophoresis voltage of $15.0 \mathrm{kV}$, and a running temperature of $35^{\circ} \mathrm{C}$. The syringe pumping time necessary to achieve complete polymer replacement in the capillary varied with polymer type and concentration. A CCD camera fitted to the ABI 310 Genetic Analyzer was used to detect fluorescence at wavelengths from 525 to $650 \mathrm{~nm}$. Virtual filter sets were optimized for the ABI PRISM dye set (6FAM), and dyes were excited with a $10 \mathrm{~mW}$ argon ion laser at $488 \mathrm{~nm}$ and $514 \mathrm{~nm}$.

\section{Results and Discussion}

\section{Development of the CE-SSCP-PCR method}

Control of foodborne pathogens in livestock and in the environment is important because these pathogens could contaminate animal-derived food products (Altekruse et al., 1999; McNallay et al., 2004). Ten food-borne patho- gens, Salmonella enterica, S. aureus, V. parahaemolyticus, C. perfringens, L. monocytogenes, E. coli $\mathrm{O} 157: \mathrm{H} 7$, B. cereus, C. jejuni, Y. enterocolitica, and E. sakazakii, were therefore selected as a model set for the development of a CE-SSCP method capable of the simultaneous detection of these 10 target microbes.

As pieces of single-stranded DNA from the same amplicon can have different sequences, resulting in different CE-SSCP elution times, CE-SSCP analysis can discriminate between differences in the conformations of singlestranded DNA molecules (Andersen et al., 2003; Shin et al., 2010; Wesche et al., 2005). In contrast, PCR can be used to identify pathogens based on sequence, leading us to perform PCR analysis on our DNA mixture of 10 pathogens prior to CE-SSCP. In total, six primer sets were tested for their ability to amplify the V2, V4, and V8 regions of 16S rRNA (Gillman et al., 2001), as each region was amplified using identical primer sets where either the forward or reverse primer was fluorescently labeled. Although the V2 region is reported to be the most variable region in the 16S rRNA gene (Andersen et al., 2003; Kullen et al., 2000), our results demonstrate that the primer set targeting the V4 region of the 16S rRNA with a fluorescently labeled forward primer produced the best resolution and allowed 10 peaks corresponding to our 10
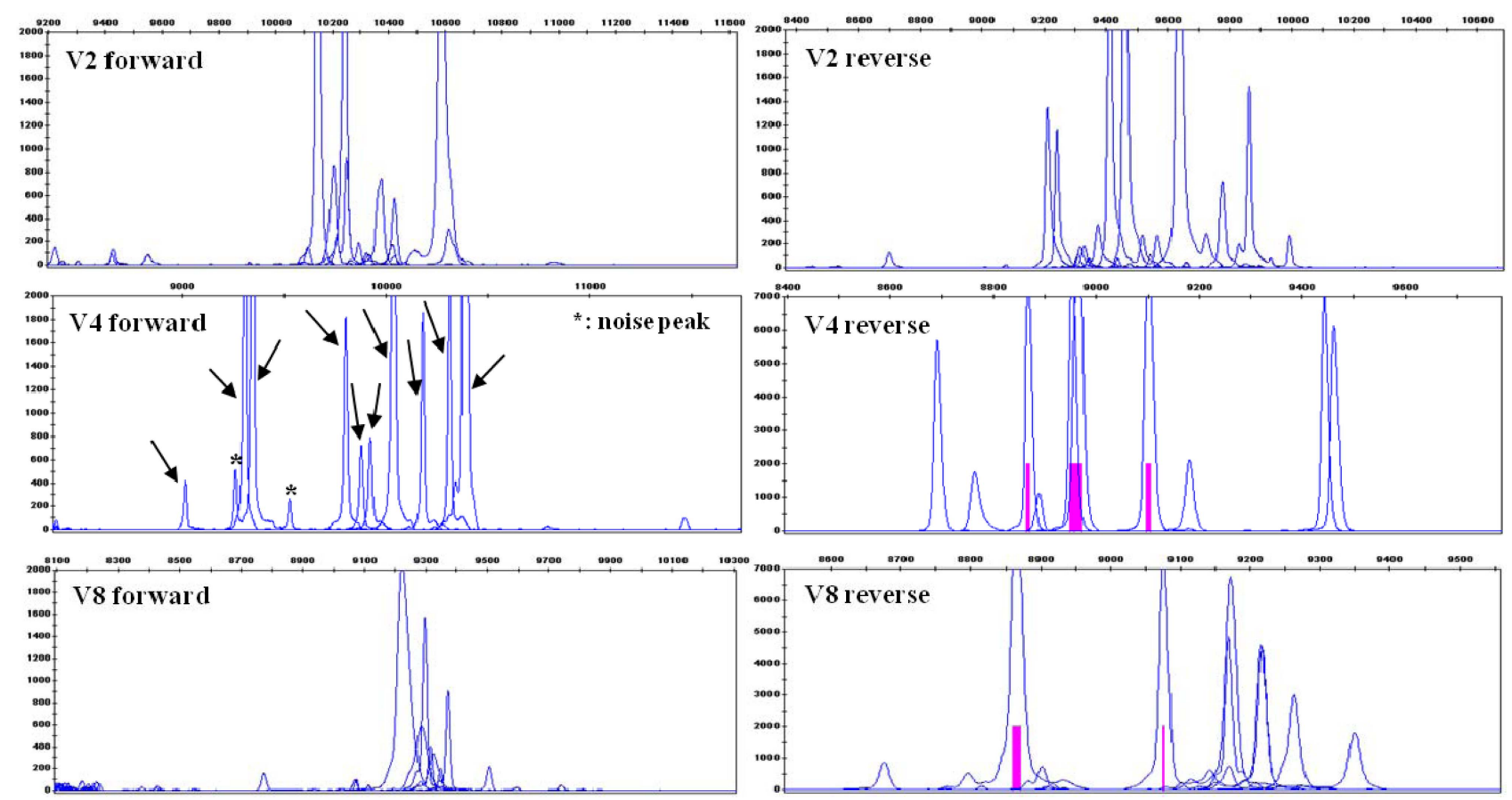

Fig. 1. Electropherograms showing the results of CE-SSCP following the PCR amplification of the V2, V4, and V8 regions of the 16S rRNA genes of 10 pathogenic species, including Salmonella enterica, Listeria monocytogenes, Escherichia coli 0157:H7, Campylobacter jejuni, Staphylococcus aureus, Bacillus cereus, Clostridium perfringens, Yersinia enterocolitica, Vibrio parahaemolyticus, and Enterobacter sakazakii. The forward or reverse indicate fluorescently labeled primer. 

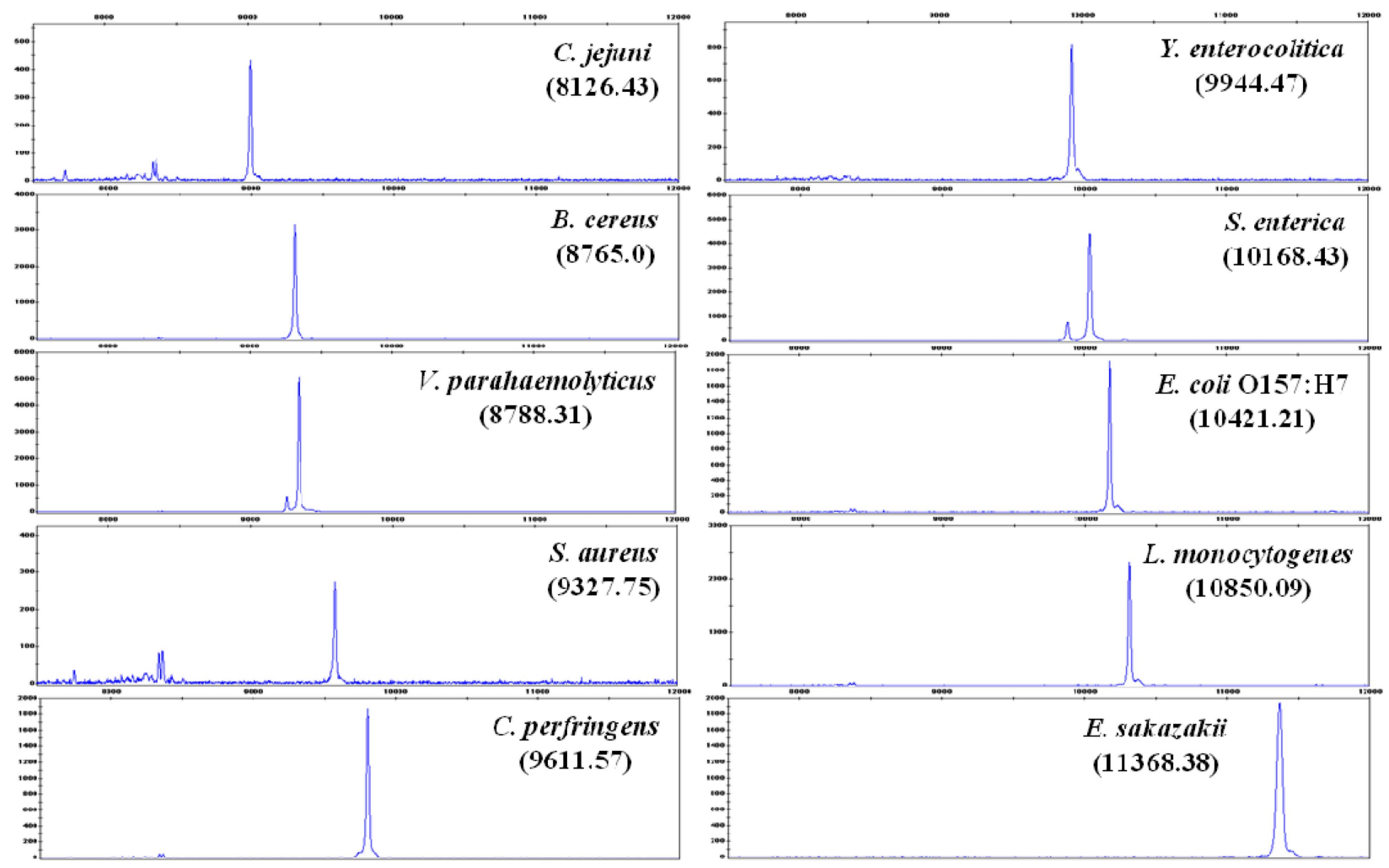

Fig 2. Electropherograms of CE-SSCP electrophoresis for the V4 region of the $16 \mathrm{~S}$ rRNA genes of 10 pathogenic microbes.

target organisms to be separated by CE-SSCP (Fig. 1).

This finding is similar to that of a study (Claesson et al., 2010) that examined several variable regions, including V1 forward-V2 reverse, V2 forward-V3 reverse, V3 forward-V4 reverse, V4 forward-V5 reverse, V5 forwardV6 forward, and V7 forward-V8 reverse, and showed that the combination of V3 forward-V4 reverse, and V4 forward-V5 reverse primers had the best predictive power for strain identification. The V4 region of the 16S rRNA may therefore have more variable sequences than other regions for our target bacteria. However, the separation power of different primers might differ among target microbial strains. Therefore, all of the primer sets used in this study should be tested before choosing the most appropriate primer set for other target organisms.

\section{Identification and separation of peaks in CE-SSCP}

We analyzed the ability of our CE-SSCP method to identify pathogenic species from a mixed culture of 10 target microbes. All strains in Table 1 were analyzed individually, and the same species showed the same retention times in CE-SSCP (Fig. 2). Our results demonstrate that the peaks corresponding to each individual strain from our pathogen mixture have identical retention times to those observed when single strains were analyzed (Fig.
3). The accurate identification of identical peaks corresponding to each species was verified with CE-SSCP by systemically changing the concentrations of each strain, as this resulted in changes to the area of the peak corresponding to that target strain without affecting the other peaks (data not shown). Using this method, 1 to $100 \mathrm{pg}$ of genomic DNA per $\mu \mathrm{L}$ was detected, which is equivalent to $10^{1}$ to $10^{3} \mathrm{CFU} / \mathrm{mL}$ (Oh et al., 2009; Zheng et al., 2004). Although the electropherograms showed smaller noise peaks in addition to the major peaks (Fig. 3), the retention times of these peaks differed from those of the peaks corresponding to the target organisms and did not interfere with the results. Further, the peaks corresponding to $B$. cereus and $V$. parahaemolyticus are not distinctly separated because of the similar three-dimensional conformations of these organisms. However, these peaks can be differentiated on the basis of the exact and reproducible retention time corresponding to each organism (8765.0 vs 8788.31, respectively) as shown in Figs. 2 and 3.

In conclusion, we demonstrated a diagnostic system that was developed using CE-SSCP and PCR. Traditional detection techniques are time consuming and labor intensive because each target species needs to be cultivated separately. In contrast, this method can simultaneously detect 10 foodborne pathogens within $5 \mathrm{~h}$. The control of 


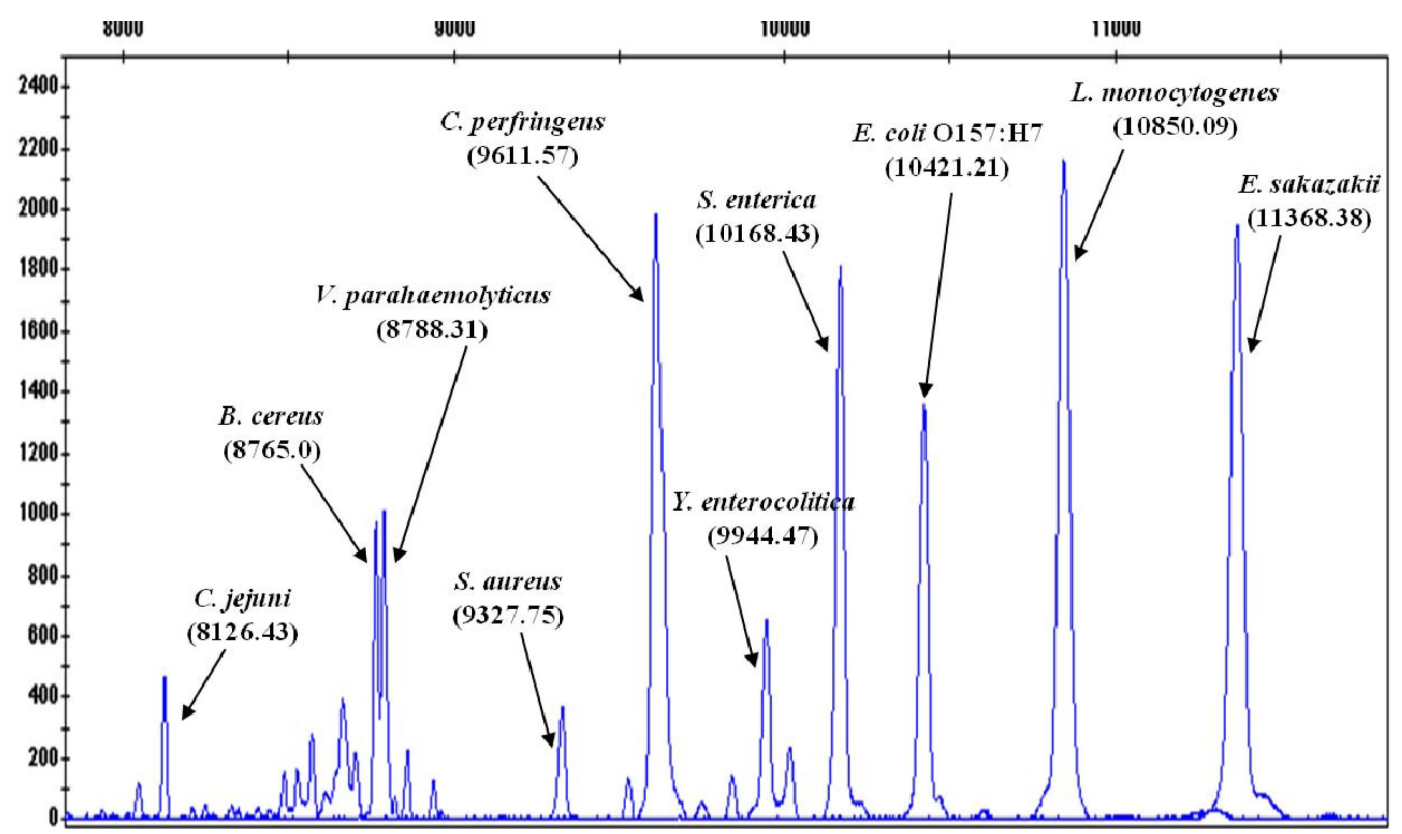

Fig. 3. Electropherograms showing the results of CE-SSCP of a mixture of 10 target microbes. The $\mathrm{x}$ and y axes represent data points and fluorescence intensity, respectively.

such pathogens is important for the animal-derived food industry, accordingly, this method can be used to provide an early warning of the outbreak of foodborne diseases. However, this method needs to be validated further, using actual food products, before it is used for the management of food safety in industry.

\section{Acknowledgements}

This work was carried out with the support of "Cooperative Research Program for Agriculture Science and Technology Development" Rural Development Administration, Korea.

\section{References}

1. Altekruse, S. F., Stern, N. J., Fields, P. I., and Swerdlow, D. L. (1999) Campylobacter jejuni - An emerging foodborne pathogen. Emer. Infec. Dis. 5, 28-35.

2. Andersen, P. S., Jespersgaard, C., Vuust, J., Christiansen, M., and Larsen, L. A. (2003) Capillary electrophoresis-based single strand DNA conformation analysis in high-throughput mutation screening. Hum. Mutat. 21, 455-465.

3. Animal Plant and Fisheries Quarantine and Inspection Agency. Standard for processing and ingredients of specifications livestock products. Available from: http://www.nvrqs.go.kr/Ex_ Work/Scflp/Livestock/View.asp. Accessed Jun. 21, 2011.

4. Claesson, M. J., Wang, Q., O'Sullivan, O., Greene-Diniz, R., Cole, J. R., Ross, R. P., and O'Toole, P. W. (2010) Comparison of two next-generation sequencing technologies for resolving highly complex microbiota composition using tan- dem variable 16S rRNA gene regions. Nucl. Acids Res. 38, $1-13$.

5. Gillman, L. M., Gunton, J., Turenne, C. Y., Wolfe, J., and Kabani, A. M. (2001) Identification of Mycobacterium species by multiple-fluorescence PCR-single-strand conformation polymorphism analysis of the $16 \mathrm{~S}$ rRNA gene. J. Clin. Microbiol. 39, 3085-3091.

6. Gracias, K. S. and Mackillip, J. L. (2004) A review of conventional detection and enumeration methods for pathogenic bacteria in food. Can. J. Microbiol. 50, 883-890.

7. Iversen, C. and Forsythe, S. (2003) Risk profile of Enterobacter sakazakii, an emergent pathogen associated with infant milk formula. Trend. Food Sci. Technol. 14, 443-454.

8. Jos Van, A., Francis, D. S., Gaetan, M., Adel, B., Anne, N., and Sabine, L. (2001) Outbreak of necrotizing Enterocolitis associated with Enterobacter sakazakii in powdered milk formula. J. Clin. Microbiol. 39, 293-297.

9. Kullen, M. J., Sanozky-Dawes, R. B., Crowell, D. C., and Klaenhammer, T. R. (2000) Use of the DNA sequence of variable regions of the $16 \mathrm{~S}$ rRNA gene for rapid and accurate identification of bacteria in the Lactobacillus acidophilus complex. J. Appl. Microbiol. 89, 511-516.

10. Larsen, L. A., Jespersgaard, C., and Andersen, P. S. (2007) Single-strand conformation polymorphism analysis using capillary array electrophoresis for large-scale mutation detection. Nat. Protoc. 2, 1458-1466.

11. McNally, A., Cheasty, T., Fearnley, C., Dalziel, R. W., Paiba, G. A., Manning, G., and Newell, D. G. (2004). Comparison of the biotypes of Yersinia enterocolitica isolated from pigs, cattle and sheep at slaughter and from humans with yersiniosis in Great Britain during 1999-2000. Lett. Appl. Microbiol. 39, 103-108.

12. Oh, M. H. and Cox, J. M. (2009) Toxigenic bacilli associated 
with food poisoning. Food Sci. Biotechnol. 18, 594-603.

13. Oh, M. H., Park, Y. S., Paek, S. H., Shin, G. W., Kim, H. Y., Jung, G. Y., and Oh, S. (2009) Simultaneous identification of seven food-borne pathogens and Escherichia coli (pathogenic and non-pathogenic) using capillary electrophoresisbased single-strand conformation polymorphism coupled with multiplex PCR. J. Food Prot. 72, 1262-1266.

14. Sakamoto, M., Takeuchi, Y., Umeda, M., Ishikawa, I and Benno, Y. (2001) Rapid detection and quantification of five periodontopathic bacteria by real-time PCR. Microbiol. Immunol. 45, 39-44

15. Shin, G. W., Cho, Y. S., Hwang, H. S., Park, J. H., and Jung, G. Y. (2008) A two-step quantitative pathogen detection system based on capillary electrophoresis. Anal. Biochem. 383, 31-37.

16. Shin, G. W., Hwang, H. S., Seo, S. W., Oh, M. H., Ryu, C. Y., Salvo, C. J., Feldman, S., Doh, J., and Jung, G. Y. (2010) A novel pathogen detection system based copolymer matrix. $J$. Sep. Sci. 33, 1639-1643.

17. Wesche, H., Xiao, S. H., and Young, S. W. (2005) High throughput screening for protein kinase inhibitors. Comb. Chem. High Through. Screen 8, 181-195.

18. Zheng, W., Spencer, R. H., and Kiss, L. (2004) High throughput assay technologies for ion channel drug discovery. Assay. Drug Dev. Ttechnol. 2, 543-552.

19. Zinger, L., Gury, J., Giraud, F., Krivobok, S., Gielly, L., Taberlet, P., and Geremia, R. A. (2007) Improvements of polymerase chain reaction and capillary electrophoresis singlestrand conformation polymorphism methods in microbial ecology toward a high-throughput method for microbial diversity studies in soil. Microb. Ecol. 54, 203-216.

(Received 2011.11.1/Revised 2012.3.26/Accepted 2012.4.3) 